RESEARCH NOTE

\section{Comparison of the Blood Meal Size among Triatoma infestans, $T$. guasayana and $T$. sordida (Hemiptera: Reduviidae) of Argentina under Laboratory Conditions}

\section{Silvia Pietrokovsky, Victoria Bottazzi, Nicolás Schweigmann, Ana Haedo, Cristina Wisnivesky-Colli ${ }^{+}$}

Unidad Ecología de Reservorios y Vectores de

Parásitos, Departamento de Ciencias Biológicas, Facultad de Ciencias Exactas y Naturales, Pabellón II, $4^{\circ}$ Piso, Ciudad Universitaria, 1428 Núñez, Buenos Aires, Argentina

Key words: blood meal size - Triatoma guasayana Triatoma sordida - Triatoma infestans

Recent studies performed in the Chaco forest of Santiago del Estero, Argentina, suggested the existence of a wild Trypanosoma cruzi cycle, which would involve opossums as main reservoirs of this protozooa and Triatoma guasayana Wygodzinsky \& Abalos and T. sordida Stal as its triatomine vectors (N Schweigmann 1994 Doctoral Thesis University of Buenos Aires). In addition, they were the only wild triatomines found in the peridomiciles of that rural area (P Gajate et al. 1993 Medicina 53: 76). Therefore, aiming to achieve a better knowledge of their efficiency as vectors of T. cruzi, we decided to carry out several biological studies on these species.

Some authors have found a positive correlation between the amount of ingested blood by different triatomines and their subsequent infection rate by $T$. cruzi (DM Minter et al. 1978 Trans $R$ Soc Trop Med Hyg 72: 84-91, DA Mello, C Chiarini 1980 Rev Brasil Biol 40: 327-334). Moreover, the developmental stage of triatomines would also modulate the infection outcome (NR Phillips,

\footnotetext{
This research work was performed with the financial support of the Secretaría de Ciencia y Técnica of the Universidad de Buenos Aires, Argentina.

+Corresponding author. Fax: 54-1-373.6102

Received 16 May 1995

Accepted 3 January 1996
}

DS Bertram 1967 J Med Entomol 4: 168-174). Since the meal size may affect the vectorial capacity of triatomines, we compared this variable among third and fifth instars of T. guasayana, T. sordida and $T$. infestans.

All nymphs used in this experiment were provided by the insectary of the Servicio Nacional de Chagas, Córdoba, Argentina. Third and fifth instars of the three species were arranged in six groups consisting of 50 insects each throughout the experiment. Jars containing triatomines were kept at $28^{\circ} \mathrm{C}$ and $70 \% \mathrm{RH}$ and exposed to a photoperiod of 11:13 (L:D).

After a 20-day-starvation period, the mean initial weights of the species-instars mentioned above were obtained by weighing ten batches of five individuals each. Then, insects were allowed to feed ad libitum during an hour on a restrained chicken and weighed again individually. The meal weight, defined as the difference between the final weight of each triatomine and the mean initial weight, was used as an indicator of the meal size.

Literature data indicate that a profuse diuresis takes place after feeding (SH Maddrell 1964 J Exp Biol 41: 163-176). To obtain a constant value reached after diuresis, the fully engorged insects of each group were weighed individually at hours $0,4,12$ and 16 after feeding. The four mean meal weights thus obtained were compared by ANOVA and Scheffé tests. Results showed that mean weights from hours 12 and 16 were not significantly different in all experimental groups. Therefore, the meal weights obtained at hour 12 were chosen to compare instars and species by a two way ANOVA and Scheffé tests.

The mean initial weight and the meal weight of the studied triatomines and their standard errors are shown in the Table. T. infestans evidenced the largest meal weight and $T$. sordida the lowest $(\mathrm{p}<0.05)$. As expected, fifth nymphs took larger meals than third nymphs $(\mathrm{p}<0.05)$, and for both stages $T$. infestans ranked first $(\mathrm{p}<0.05)$. T. sordida third and fifth instars showed a mean initial weight about 3/4 of $T$. guasayana's initial weight (Table) in spite of the fact that the meal weight of their third nymphs showed no significant differences. However, T. guasayana fifth nymphs ingested a larger bloodmeal than that of $T$. sordida $(\mathrm{p}<0.05)$. This lack of linear relationship between the mean initial weight and the size of the bloodmeal when we compared the same instars of various triatomine species had also been observed by AP Szumlewicz (1975 Laboratory colonies of triatominae p. 6382. In PAHO-WHO American Tripanosomiasis Research Brazil).

The blood meal differences observed among the studied triatomines suggest that after the in- 
TABLE

Mean initial and meal weights ( \pm SE) of third and fifth nymphs of Triatoma infestans, $T$. guasayana and $T$. sordida, obtained after the diuresis period

\begin{tabular}{|c|c|c|c|c|}
\hline \multirow[b]{2}{*}{ Species } & \multicolumn{2}{|c|}{$\begin{array}{l}\text { Mean initial weight }{ }^{a} \pm \text { SE } \\
(\mathrm{mg})\end{array}$} & \multicolumn{2}{|c|}{$\begin{array}{c}\text { Mean meal weight }{ }^{b} \pm \mathrm{SE} \\
(\mathrm{mg})\end{array}$} \\
\hline & \multicolumn{4}{|c|}{ Instar } \\
\hline & Third & Fifth & Third & Fifth \\
\hline T. infestans & $7.8 \pm 0.19$ & $73.8 \pm 3.70$ & $22.13 \pm 1.12$ & $147.43 \pm 6.93$ \\
\hline T. guasayana & $5.2 \pm 0.23$ & $47.4 \pm 2.64$ & $12.98 \pm 0.34$ & $115.06 \pm 5.02$ \\
\hline T. sordida & $3.8 \pm 0.09$ & $38.5 \pm 2.07$ & $11.96 \pm 0.40$ & $68.91 \pm 3.05$ \\
\hline $\bar{X}$ & & & $15.69 \pm 0.56$ & $110.57 \pm 4.01$ \\
\hline
\end{tabular}

$a$ : obtained from starved nymphs, 20 days after their last moult.

$b$ : mean meal weigth $=$ final weight - initial weight. It was obtained from 50 triatomines per group. Final weights at hour 12 after feeding were chosen to calculate the meal weight of each group.

gestion of T.cruzi contaminated blood T. infestans would have more chance to acquire the infection than T. guasayana or T. sordida, and between the wild species, $T$. guasayana would reach the highest infection rate. The interaction between the triatomine vector and the parasite constitutes a complex system involving several factors such as the insect age and the number of parasites ingested by the bug, as well as the intensity of host parasitemia, the $T$. cruzi strain and the reciprocal adaptation between the vector and the parasite (R Zeledón 1987 Chagas' Disease Vectors Vol II: 59-75, ES Garcia, P Azambuja 1991 Parasitol Today 7: 240244). Triatomines show different susceptibility to different parasite populations, and this may explain why some authors found a relationship between the blood meal size and the infection rate for different triatomine species while others did not (MA
Miles et al. 1975 Trans R Soc Med Hyg 69: 377382).

However, it is clear that a species intaking larger blood meals would have a higher probability of becoming infected when it feeds on a host undergoing the chronic phase of the infection. RA Neal and RA Miles (1977 Rev Inst Med Trop São Paulo 19: 177-181) stated that the distribution of trypomastigotes in the blood stream is more uniform in high than in low intensity infections because in the latter parasites are released asinchronically and the time lapse in which they are circulating varies.

Further work involving local T. cruzi populations is needed to determine whether $T$. guasayana and $T$. sordida are good vectors in the wild and/or the domestic cycles of the Chaco Region of Argentina. Current studies undergoing in our laboratory may reveal some aspects about this point. 